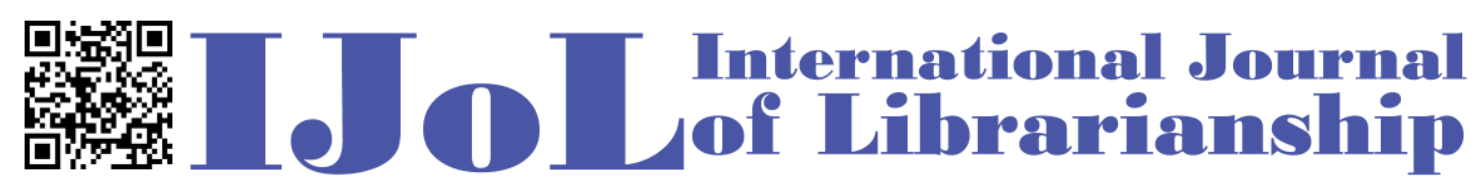

ISSN: 2474-3542 Journal homepage: http://journal.calaijol.org

\title{
Automating Cataloging Workflow of Library Traditional Materials
}

\author{
Elaine Dong
}

\begin{abstract}
:
This paper describes the author's experience with automating and streamlining cataloging workflows of traditional materials at the Florida International University Libraries using a combination of various cataloging tools, including MarcEdit, a local batch loading tool GenLoad, as well as OCLC services including WorldCat Updates service, OCLC Connexion's batch process searches and Local File Manager. The paper addresses the old cataloging processes of these traditional materials, the developing process of new workflows and their impacts, and concludes with lessons learned and success factors. The new workflows have improved work efficiency and metadata control. The hope is that this paper will be of interest to libraries desiring to automate their cataloging workflow of traditional materials.
\end{abstract}

To cite this article:

Dong, E. (2021). Automating cataloging workflow of library traditional materials.

International Journal of Librarianship, 6(1), 73-88.

https://doi.org/10.23974/ijol.2021.vol6.1.183

To submit your article to this journal:

Go to https://ojs.calaijol.org/index.php/ijol/about/submissions 


\title{
Automating Cataloging Workflow of Library Traditional Materials
}

\author{
Elaine Dong \\ Florida International University, FL, USA
}

\begin{abstract}
This paper describes the author's experience with automating and streamlining cataloging workflows of traditional materials at the Florida International University Libraries using a combination of various cataloging tools, including MarcEdit, a local batch loading tool GenLoad, as well as OCLC services including WorldCat Updates service, OCLC Connexion's batch process searches and Local File Manager. The paper addresses the old cataloging processes of these traditional materials, the developing process of new workflows and their impacts, and concludes with lessons learned and success factors. The new workflows have improved work efficiency and metadata control. The hope is that this paper will be of interest to libraries desiring to automate their cataloging workflow of traditional materials.
\end{abstract}

Keywords: Batch Cataloging, Batch Processing, Batch Searching, Batch Loading, Traditional Materials

\section{INTRODUCTION}

Over the last decade, cataloging departments in academic libraries have seen many challenges, especially during difficult economic times. The budget and staff size have been reduced while workload remains the same or is increasing; simultaneously, cataloging staff are expected to keep up with new technology and emerging areas of focus. Facing these challenges, cataloging staff in academic libraries have explored ways to streamline cataloging workflows of traditional materials through batch processing using OCLC services and other tools. Barbara Anderson described her experience of using the WorldCat Updates service and load services of the Alma library system to batch process and batch upgrade the local bibliographic (bib) records that have OCLC numbers in the institutional zone at Virginia Commonwealth University (2015). Similarly, Grace Riordan and Corinna M. Baksik used the WorldCat Updates service to batch process and enhance their book records in the local catalog at Harvard Library (2017). Nancy Lorimer described a project that uses OCLC Connexion's batch-processing utility to batch search OCLC records of $78 \mathrm{rpm}$ sound recordings, and batch loaded the matching OCLC records using some locally developed program (2012). Jean Harden discussed how to expedite the cataloging of similar items, such as a large stack of piano etudes, using OCLC Connexion's batch-processing utility to batch search OCLC records for the library items, using Microsoft Access to enter data for the items without OCLC records, and then processing it through MarcEdit and importing it into Connexion to create original 
records for those items (2017). In order to enhance the records of the main circulating collection by batch adding contents notes and Library of Congress Classification numbers, Buswell Memorial Library at Wheaton College used MarcEdit's Z39.50 client, batch searching service in OCLC Connexion, and the bulk import function in the local catalog (Strickler, 2017). Most recently, Rebecca B. French developed a method to batch catalog a Jazz LP Collection using the Connexion batch searching service, local save file manager, and Microsoft Access at James Madison University (2020).

At Florida International University (FIU) Libraries, most of the library's traditional materials were cataloged individually, and a backlog was developed due to the complex process of traditional cataloging. The author of this paper has batch loaded MARC records of e-resources into the local catalog using a locally developed batch loading tool called GenLoad ${ }^{1}$ at the FIU Libraries for many years. The batch loading process helps provide timely access to the increasing amounts and variety of e-resources. In order to eliminate the backlog of the traditional materials waiting to be cataloged and to improve work efficiency, the author investigated various ways of using the batch loading process with other cataloging tools to expedite the cataloging process of some traditional materials, including two print approval collections and one music collection. For one print approval collection, WorldCat Updates service ${ }^{2}$ was used to collect upgraded OCLC master records and then GenLoad was used to batch load the upgraded records into the local catalog. For the other print approval collection and the classical music collection, OCLC Connexion's batch process searches and Local File Manager ${ }^{3}$ were used to batch search OCLC records for library copies and editing records. MarcEdit ${ }^{4}$ was used to batch retrieve OCLC master records and then GenLoad was used to batch load the upgraded records into the local catalog. The new workflows have largely improved cataloging efficiency and metadata quality.

\section{BACKGROUND}

The FIU Libraries migrated from Northwestern Online Total Integrated System (NOTIS) ${ }^{5}$ to the Aleph Integrated Library System ${ }^{6}$ in 2006. In June 2012 the FIU Libraries' catalog was merged into the Shared Bib (SB), a consortium library catalog consisting of shared records of 12 State University Libraries (SULs) in Florida. Since then, the FIU Libraries has followed the cooperative principle of sharing and maintaining bib records among the member SULs: before bringing in new records to the SB, library staff from the SULs searches the SB to ensure duplicate bib records are not generated; if a bib record already exists for the searched title, the staff adds the institutional holdings and item record to the bib record.

Currently, there are three ways to add records into the SB: the first is to catalog the item individually, either through original cataloging by creating an original OCLC record and exporting it into the SB or through copy cataloging - finding a pre-existing OCLC record, editing it if necessary, and exporting it into the SB. The second method is to batch load MARC records through GenLoad, a batch loading program created by the Florida Center for Library Automation (FCLA), ${ }^{7}$ the predecessor of the Florida Academic Library Services Cooperative (FALSC); ${ }^{8}$ and the third way is to batch load brief vendor acquisition records with orders through Aleph Advanced Generic Record Loader (P-file 90). ${ }^{9}$

The Green Library, the main library of the FIU Libraries, received the majority of new print books through approval plans: specifically, the YBP approval plan (contract with Yankee 
Book Peddler, Inc. (YBP) Library Services for U.S. and U.K. publishers), and Latin American and Caribbean collections (LAC) approval plans covering publications from Caribbean and Latin American countries. The Green Library also purchases physical audiovisual materials such as LPs, CDs, and DVDs to support curricular and research needs. In the past, most of these traditional materials were cataloged individually, and a backlog was developed due to the complex processes of traditional individual cataloging. Cataloging staff were overwhelmed and stretched thin with the additional workload of dealing with increasing amounts of e-resources and other tasks.

\section{AUTOMATE CATALOGING WORKFLOWS OF TRADITIONAL MATERIALS}

In order to eliminate the backlog of these traditional materials and improve work efficiency, the author investigated various services and tools in order to automate and streamline the cataloging workflows of the following three collections: YBP print approval books, Latin American and Caribbean Collections (LAC) print approval books, and a classical music LP collection. Below, the author describes the old cataloging process, new workflow, and its impact for each collection.

FIU Green Library received weekly shipments of new print books through the YBP approval plan (about 10,000 titles per year, majority of them are published in English) until 2018 when the plan was migrated to an ebooks patron-driven acquisitions (PDA) plan.

Old Process (before April 2015)

Prior to June 2007, YBP print approval books were cataloged individually in-house and cataloging staff did all the physical processing. In June 2007, the Green Library added shelf-ready services to their contract with YBP Library Services. This new service included physical processing of the books (new books come in with property stamps, magnetic strips, barcodes, and spine labels already attached), and MARC records of the new books through OCLC PromptCat service, ${ }^{10}$ so they can be batch loaded to the library catalog. Our initial reviews found errors in many MARC records; therefore, in order to maintain high quality metadata and assure accurate access, from June 2007 to April 2015, the Cataloging Department adopted the following workflow for YBP approval books:

After receiving books and their MARC records, GenLoad was used to sort out DLC records (DLC records are created by the Library of Congress and regarded as top quality records that do not need further review), and then batch loaded these DLC records into the library catalog by GenLoad. These books (about 4,000 books, $40 \%$ of total) were sent directly to circulation to be shelved. For the remaining books (about 6,000 books, $60 \%$ of the total), their MARC records were batch loaded to the library catalog using a different GenLoad loading profile which generates FIU holdings and items with a status of incomplete cataloging. The online public access catalog (OPAC) displays these books as "in process." These books stayed in the Cataloging Department until they were examined and upgraded individually.

At the beginning of 2015, there was a backlog of several thousand physically processed YBP books sitting in the Cataloging Department, and several hundred associated names and series waiting to be established. 
Developing New Processes (February - April 2015)

In order to get the backlog under control, the YBP Approval Process Task Force as well as the Authority Work Task Force, both composed of the Cataloging Department head and several department staff members, were formed in early 2015 to find more efficient ways of processing these books. For the YBP approval process, we decided to use the WorldCat Updates Service to collect upgraded full-level ${ }^{11}$ OCLC master records, and then use GenLoad to batch load the fulllevel OCLC records into the SB, which would replace the individual upgrading process of the old workflow. For the authority work, since most of full-level OCLC master records include established headings backed by complete authority work, we decided to rely on the above upgrading process for authority control and stop doing individual authority work on YBP print approval books, allowing us to focus our individual authority work on non-English language materials, special collections, and other unique collections.

The WorldCat Updates service is now a part of WorldShare Collection Manager, ${ }^{12}$ and can be set up to receive updated records when selected OCLC master records matching specified criteria (in FIU's case, YBP approval PromptCat records) are enhanced. In WorldShare Collection Manager, the author created a query collection YBP15- for the FIU YBP approval books and set up the collection selection criteria (Figure 1). The query collection automatically harvests OCLC records that meet the following criteria: li (library): FXG (the symbol of FIU Green Library) AND vn (Vendor): YBP AND yr (publication year): 2015..9999 (published since 2015) AND mt (material type): bks (books) NOT mt (material type): elc (electronic resources). In other words, the collection hosts OCLC records that: a) have FIU Green Library's holdings; b) created or ordered by YBP (OCLC records have Marc 938 field indicating vendor records of YBP); c) published since 2015; and d) material type is book, but not electronic resources.

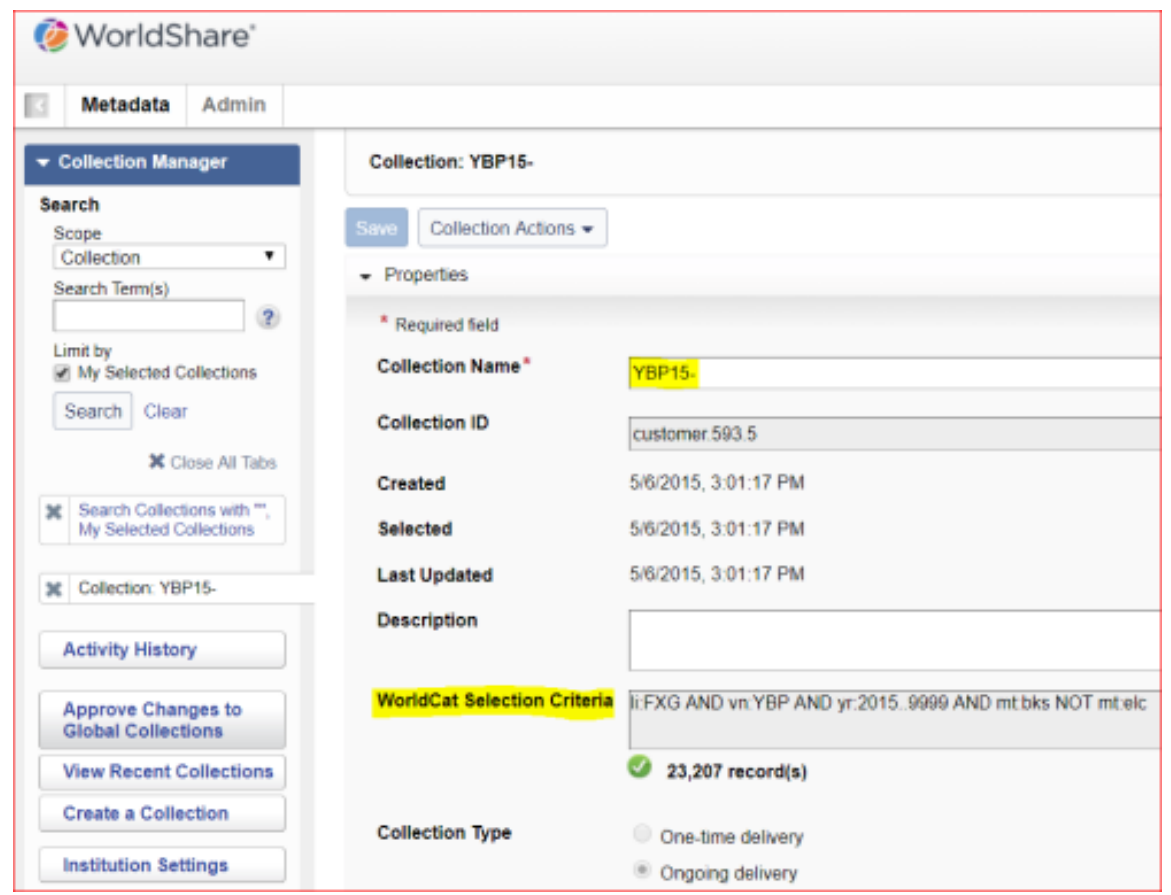

Figure 1. Query Collection YBP15- and Selection Criteria 
For the query collection, it was set up to receive upgraded records biweekly when the OCLC master records met either one of the following conditions (Figure 2):

- Encoding levels (Elvl) changed to full-level, indicated by Elvl=Blank, I, 1, or L

- MARC 830 field changes (indicating series authority record is established or modified)

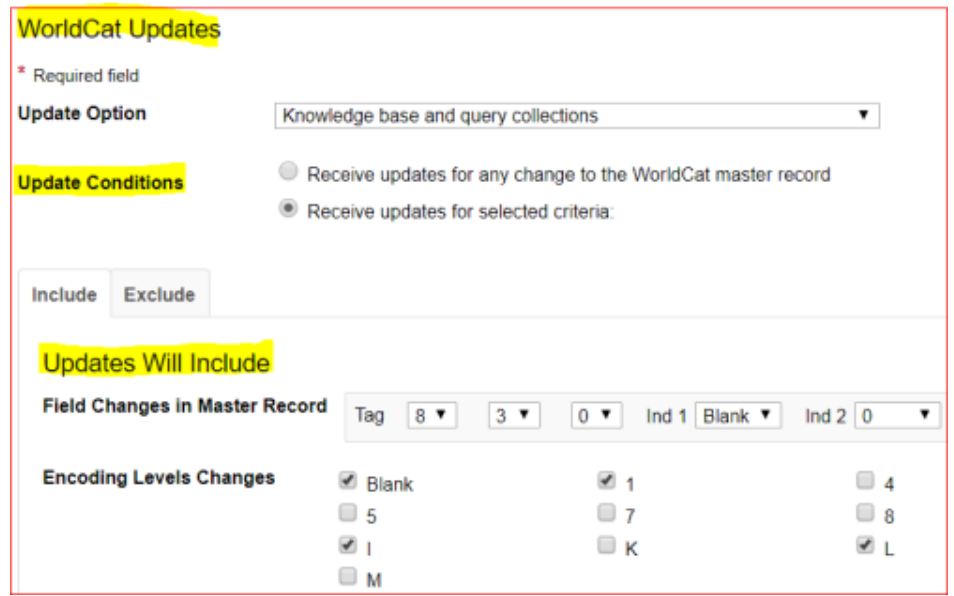

Figure 2. WorldCat Updates service - Update Conditions

After receiving the upgraded full-level OCLC MARC records from the WorldCat Updates service, the next step is to load these OCLC records by GenLoad to batch update existing SB records. For this purpose, a GenLoad profile was created and set to match the OCLC MARC records with the SB records by OCLC number, and to batch update the matching bib records (not FIU holdings or item records) in the SB while protecting local data such as local notes in Marc 590 field.

During test runs, a small percentage (about 5\%) of upgraded OCLC records couldn't find matching records in the SB since the corresponding OCLC master records of these SB records were merged with better OCLC records. For these cases, the old OCLC numbers in MARC 035 fields of SB records need to be replaced manually with the new OCLC numbers from the upgraded OCLC MARC records so that the existing SB records could be replaced by better OCLC records through batch upgrading process.

New Workflow (May 2015 - present)

After the test and evaluation process, the following new workflow has been implemented since May 2015:

The first step after receiving books and their MARC records is to sort out records with complete call numbers in the Marc 050 or 090 field using GenLoad. Then batch load these records into the SB by GenLoad. The loading also creates FIU holdings and item records with a cataloging status of complete. These books (about 9,000 books, $90 \%$ of total) are sent directly to circulation to be shelved as they come with physical processing. 
The second step is to keep the remaining books (about 1,000 books, 10\% of total) in the Cataloging Department. Then batch load their MARC records into the SB by GenLoad with a different GenLoad profile, so that the loading creates FIU holdings and item records with a cataloging status of incomplete. As a result, the OPAC shows these books as "in process."

The next step is to load the upgraded OCLC MARC records received from WorldCat Updates service by GenLoad on a biweekly basis to batch update existing SB records.

Finally, the "in process" books that were updated by the batch upgrading process are identified and their cataloging process is completed using the load logs generated by GenLoad to get the associated FIU holdings of the replaced bib records. Then use an Aleph report and Excel to separate the "in process" titles. Lastly, the "in process" books are located and cataloging is completed by updating FIU holdings and item records to a status of complete according to their updated bib records.

\section{Impacts of New Workflow}

After implementing the new workflow, the following impacts were observed:

Provide users timely access: the new workflow sends about $90 \%$ (vs. $40 \%$ with the old workflow) of new YBP approval books directly to the stacks upon arrival. Users have access to these books almost immediately, and the catalog record can be enhanced without keeping the books in the Cataloging Department. The batch upgrading process updates the records of both cataloged and "in process" books, and clears the majority of the "in process" books sitting in the Cataloging Department, so very few books need to be cataloged individually. As a result, new books have been cataloged quickly with the number of YBP approval books being added to the backlog reduced largely from $60.5 \%$ in Jan. 2015 with the old process, to 8.2\% in July 2015 (two months after implementing the new workflow) as shown below in Table 1, and eventually all the backlog was eliminated.

Table 1. Backlog Information of YBP Print Approval Books

\begin{tabular}{lccc}
\hline \multicolumn{4}{c}{ YBP Print Approval Books } \\
\hline & Received & Backlogged & \% Backlogged \\
\hline Jan. 2015 with old process & 1,081 & 654 & $60.5 \%$ \\
July 2015 with new workflow & 1,359 & 111 & $8.2 \%$ \\
\hline
\end{tabular}

Save staff time: the old workflow developed a backlog despite the efforts of many hours per week of several cataloging staff members, whereas the new workflow needs only about 2 hours biweekly of two staff members.

Enhance quality control and reduce human errors: the new batch upgrading process has improved metadata quality in both bibliographic and authority records by updating the existing FIU records to full-level in the local catalog in a timely fashion. It has also reduced human errors. For example, set in the GenLoad profile, the batch loading process removes redundant MARC 
fields (such as 9xx fields and 072 field) from OCLC MARC records and protects local data before updating existing SB records. Another example is that the new workflow includes a step to check and fix the URL fields of OCLC MARC records (correct indicator errors and remove unnecessary URL fields) using MarcEdit before batch upgrading process.

\section{LATIN AMERICAN AND CARIBBEAN COLLECTIONS (LAC) PRINT APPROVAL BOOKS}

FIU Green Library receives print books through LAC approval plans from several foreign vendors (once a week mostly, about 2,000 titles per year). The majority of them are published in Spanish; the rest are published in Portuguese, Haitian Creole, or French. FIU hasn't purchased MARC records from these vendors; however, a couple of vendors, such as Iberoamericana, provide brief MARC records of their published books for free. For physical processing, acquisitions staff add magnetic strips, and cataloging staff complete the rest including adding property stamps and barcodes, and printing and applying spine labels.

Old Process (before 2018)

Before 2018, LAC approval books were cataloged in-house individually. After receiving LAC books, cataloging staff create SB records within a week so that acquisitions staff could attach order records for payment in a timely fashion. Since LAC books are non-English publications from foreign countries, many of them don't have OCLC records or established names/series readily available. For these books, cataloging staff initially create brief SB records including only a few fields to allow acquisitions to complete payment, and later on upgrade these records individually. In many cases, cataloging librarians need to create original OCLC records for some books and then overlay the brief SB records to complete their cataloging process. At the beginning of 2018, there were 413 LAC approval books waiting to be cataloged and many associated names and series needed to be established.

Developing New Process (January - February 2018)

\section{LAC Approval Books with Brief MARC records}

To improve efficiency, we worked with FALSC on developing a batch loading process for the brief MARC records (which include title, ISBN number, order information, and other fields) provided by Iberoamericana. The batch loading process was implemented in February 2018 using the Aleph Advanced Generic Record Loader (file-90), which is a perfect tool for loading these brief vendor records with order information into the SB. In October and November 2019, we replicated the batch loading process for the brief MARC records now provided by two other LAC approval plan vendors, RettaLibros and Libro Andinos. The batch processes have freed both cataloging and acquisitions staff from creating individual brief bib records and order records for half of FIU's LAC vendor books, increasing productivity.

\section{LAC approval books with OCLC Master records}

With the help of a staff member, the author developed a batch process for the LAC books with full-level OCLC master records using MarcEdit, GenLoad, and OCLC Connexion's batch process 
searches and Local File Manager. The author did the following test run on the backlog of 413 LAC books to find out whether it worked:

The first step was to call up the SB records of these LAC books by searching a standard TKR field in the holdings records (a field routinely added by FIU cataloging staff at initial processing). Then, the OCLC record numbers from the MARC 035 field on bib records (for example, $=035 \| \$ \mathrm{a}(\mathrm{OCoLC}) 25416038)$ were gathered by an Aleph report. It was discovered that all these SB records had OCLC numbers, which confirmed that, eventually, the brief SB records initially created by FIU staff were later overlaid by OCLC records brought in by other SULs. Lastly, their corresponding OCLC master records were batch retrieved using the MarcEdit Z39.50 Client's batch processing mode (Figure 3).

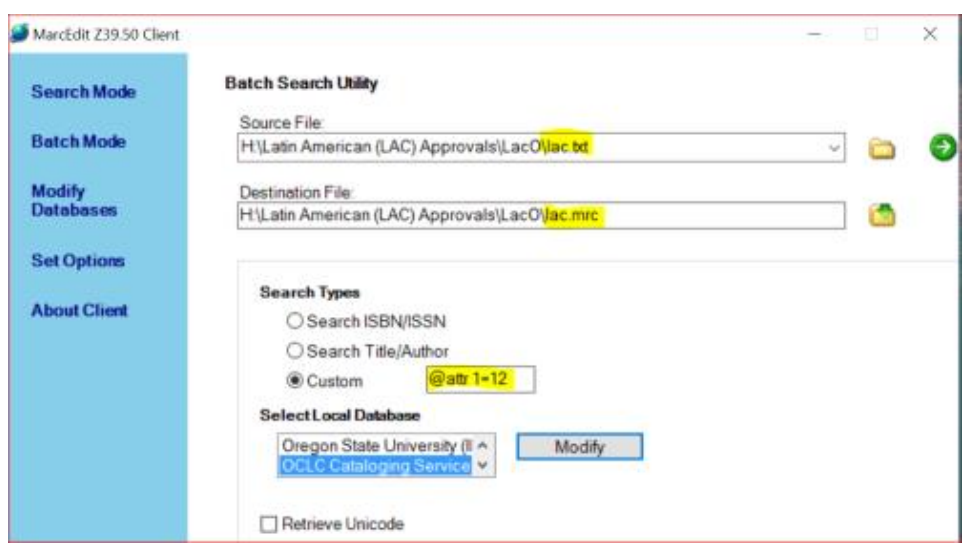

Figure 3. Batch Retrieve OCLC Records via MarcEdit Z39.50 Client

The second step involved sorting OCLC master records by GenLoad in order to separate full-level from non-full-level records. The GenLoad File Sorter identified 406 records with complete call numbers (has subfield \$b in MARC 050 or 090 field) (Figure 4) out of a total of 413 records; identified 404 records that are cataloged in English (Subfield \$b of MARC 040 field=eng), and identified and separated 341 full-level records (Marc leader field (LDR) Encoding level (position 17)= Blank, I, 1, L) from 63 non-full-level records. 


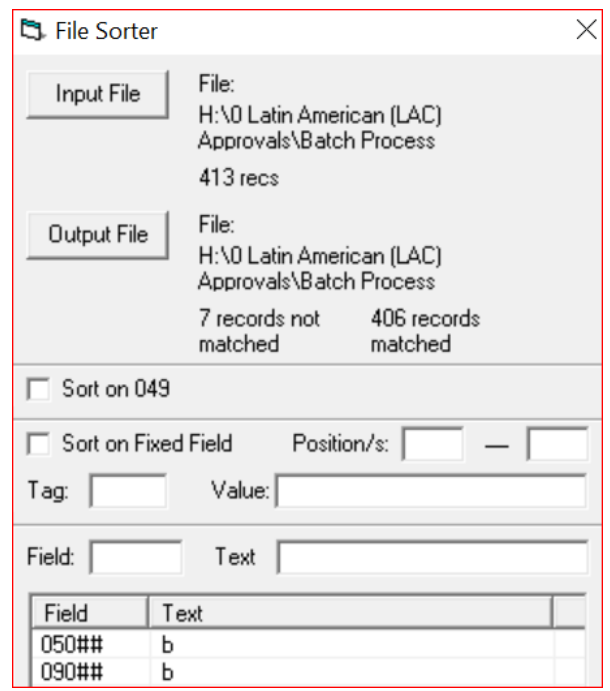

Figure 4. Sort Records with Complete Call Number via GenLoad

The third step was to review and update non-full-level OCLC master records. After batch importing the 63 non-full-level records into the OCLC local save file, the author reviewed them one by one and discovered that 53 of them are actually full-level records with established headings and complete call numbers. The author changed these 53 records' Elvl codes to full-level in OCLC, and then batch exported their MARC records.

Step four involved an authority check on full-level OCLC master records. The author checked the access points of 100 randomly selected records out of 341 full-level OCLC master records: 91 out of the 100 selected records had complete authority control, and only nine out of 100 records have incomplete authority control: among them, four have unestablished series; two have established personal headings, but their forms in the MARC records are slightly different than those of $\mathrm{NACO}^{13}$ National Authority Record (NAR); the remaining three are personal or corporate names that don't have NARs (Table 2). 
Table 2. OCLC Records with Incomplete Authority Control

\begin{tabular}{lcl}
$\begin{array}{c}\text { OCLC Record } \\
\text { Number }\end{array}$ & $\begin{array}{c}\text { Encoding } \\
\text { Level (Elvl) }\end{array}$ & \multicolumn{1}{c}{ Note } \\
975491662 & Blank & $\begin{array}{l}\text { Personal name in MARC } 100 \text { field is established; Series in } \\
\text { MARC 830 field is not established }\end{array}$ \\
1001907037 & I & has MARC 490 0_field; no MARC 830 field \\
987257621 & I & Personal name in MARC 100 field is not established \\
966300663 & I & $\begin{array}{l}\text { 2 corporate names in MARC 710 fields are established; } 1 \\
\text { personal name for editor in MARC 700 field is not established }\end{array}$ \\
988992036 & I & $\begin{array}{l}\text { Personal name in MARC } 100 \text { field is established; has MARC } \\
490 \text { field, no MARC 830 field }\end{array}$ \\
992722210 & I & $\begin{array}{l}\text { Personal name in MARC } 100 \text { field has no birth date; established } \\
\text { NAR does }\end{array}$ \\
47740852 & I & $\begin{array}{l}\text { Personal name in MARC 700 field has birth date; established } \\
\text { NAR doesn't }\end{array}$ \\
56726555 & I & Series in MARC 830 field is not established \\
26380041 & I & Corporate name in MARC 710 field is not established \\
\hline
\end{tabular}

Step five was to share information and obtain departmental approval. The author demonstrated the batch process and authority check results at the department meeting. The group discussed and approved the batch process and reached a consensus on using LAC books' full-level OCLC master records to batch upgrade the existing SB records without performing authority checks individually.

The final step was to batch load full-level OCLC master records by GenLoad to upgrade SB records. After departmental approval, the author combined all the full-level OCLC master records (394 records in total including the 341 records identified from the GenLoad sorting process and the 53 records updated from non-full-level), and batch loaded them into the SB by GenLoad. The GenLoad profile was set to match the OCLC master records with the SB records by OCLC number, then replace the matching SB bib records while protecting local data. The batch load also completed the cataloging process of these LAC books by updating the associated FIU holdings and item records to a completed status.

\section{LAC Approval Books without Full-Level OCLC Master Records}

For the remaining 19 LAC books without full-level OCLC master records (including two OCLC records not cataloged in English and seven records without a complete call number), the author changed their TKR field value in the SB holdings records, and placed them alongside 
Iberoamericana books (which had brief records loaded in the SB) on a different shelf in the Cataloging Department. The author developed a different batch process using GenLoad and OCLC Connexion's batch process searches and Local File Manager, and did the following test run on these books:

The first step was to call up the SB records of these books by searching a different TKR field value in the holdings. Then, the ISBN numbers were gathered from the MARC 020 field of the bib records by using an Aleph report. Lastly, the author batch searched in OCLC by ISBN number (Batch-Enter bibliographic search keys) (Figure 5). The search saved matched OCLC master records in an OCLC Local Save File.

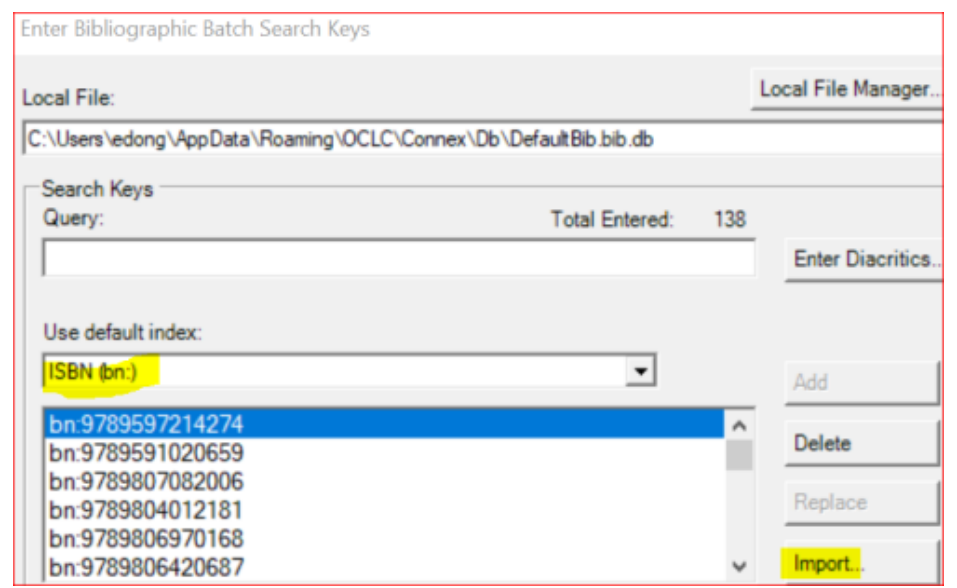

Figure 5. Batch Search Records in OCLC by ISBN Number

For the second step, the best records in the OCLC Save File were selected. The records were sorted by the column CatL (cataloging language) (Figure 6) for the purpose of removing the records not cataloged in English (CatL $\neq$ eng). Then, the records were re-sorted by the column Save File Number. Since multiple records exist for some titles, the best record for each title was selected and the other records were removed. OCLC master records with ELvl (Encoding level)=Blank, I, 1, L and most holdings are usually the best. Lastly, the selected OCLC master records in OCLC Local Save File were batch exported after updating their holdings.

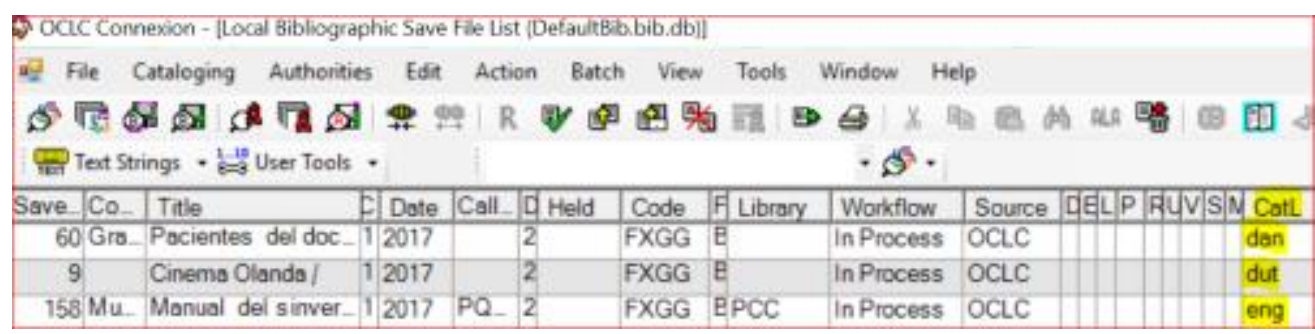

Figure 6. Sort Records by Cataloging Language in OCLC Local Save File 
The third step involved sorting OCLC master records by GenLoad to separate full-level from non-full-level records. Following the sorting, full-level OCLC records were batch loaded by GenLoad to update matching SB bib records and associated FIU holdings and item records to completed status. Non-full-level OCLC records were batch loaded using a different GenLoad profile which updates matching SB bib records and associated FIU holdings (adds a TKR field value) but not FIU items, so that associated FIU holdings and item records still have incomplete status.

The LAC books without any OCLC master records were kept on the same shelf for future batch process or original cataloging.

The new batch processes for LAC print approval books have been implemented since February 2018. The new LAC processes have helped us eliminate the LAC approval book backlog. Additionally, as with the new workflow for the YBP print approval books, it has had a positive impact on providing timely access of books, saving staff time, reducing human errors, and has improved cataloging efficiency and metadata quality.

\section{CLASSICAL MUSIC LP (LONG PLAY) COLLECTION}

FIU Green Library houses a donated classical music sound recording collection consisting of over 12,000 recordings, mostly in LP format. This collection was slowly being cataloged since its receipt.

Old Process $(1 / 2013-8 / 2017)$

In the past, music recordings from this collection were cataloged in-house individually except for about 1,000 recordings in foreign languages outsourced to Backstage Library Works.

New Process (9/2017 - 4/2018)

In order to facilitate timely access of this valuable collection, the author developed and implemented the following batch cataloging process using MarcEdit, GenLoad, and OCLC Connexion's batch process searches and Local File Manager, which is similar to the ones for LAC approval books:

The first step was to search uncataloged music recordings by their publisher numbers (a music recording has a publisher number, instead of ISBN number, as its unique identifier) in the SB and enter their publisher numbers on a spreadsheet.

The next step was to deal with music recordings without SB records. These records were batch searched in OCLC by publisher number. The search saved matched OCLC master records in an OCLC Local Save File. Then, the best records were selected for each title in the OCLC Local Save File and exported in batch. Lastly, the OCLC master records were batch loaded by GenLoad to create new bib records and add associated FIU holdings and item records with completed status in the SB. For the music recordings without OCLC records, the cataloger conducts original cataloging.

Finally, for music recordings that found SB records (added by other SULs), the OCLC numbers from MARC 035 fields of bib records were gathered by an Aleph report. Then, a batch retrieve was performed for their OCLC master records using the MarcEdit Z39.50 Client's batch 
processing mode. Lastly, the OCLC master records were batch loaded by GenLoad to upgrade bib records and add associated FIU holdings and item records with completed status in the SB.

\section{Impact of New Process}

With about the same amount of staff working on the collection, the new process achieved 533 cataloged titles per month compared to 133 titles with the old process, and we were able to complete cataloging the remaining one third of the collection in 8 months (Table 3 ).

Table 3. Classical Music Collection Statistics

\begin{tabular}{lccc}
\hline & $\begin{array}{c}\text { Titles } \\
\text { Cataloged }\end{array}$ & Time Spent & $\begin{array}{c}\text { Titles Cataloged } \\
\text { Per Month }\end{array}$ \\
\hline Cataloged in-house by Batch Process & 4,263 & 8 months & 533 \\
Cataloged in-house individually & 7,474 & 56 months & 133 \\
Cataloged by Backstage Library Works & 1,023 & 24 months & 43 \\
Total Cataloged & & $(7 / 2015-7 / 2017)$ & \\
\hline
\end{tabular}

\section{CONCLUSION}

During this process, several lessons were learned regarding workflow changes:

- The first step before developing a new workflow is to have a thorough understanding of the old process from all the staff involved in the workflow.

- While developing a new workflow, always do a test run first on a small batch of items, and adjust and improve the workflow as needed.

- Documenting the process along the way will help in refining the procedures at a later stage.

- After the new workflow is developed, discuss it with staff for feedback.

- It's important to evaluate and assess its impact, and asking questions such as: who will be affected by the new process? Will the new process benefit them?

- After the new workflow is approved for implementation, select qualified staff for the new process.

- It's crucial to walk staff through the new process, answer their questions, and ask for their suggestions. 
- It's always necessary to follow up, collect feedback, and adjust workflow and procedure accordingly.

The author would like to share her experience with automating cataloging workflows of traditional library materials because it could be beneficial to libraries that plan to implement automation workflows in cataloging. Overall, the author's experience has been highly positive: the batch processes and various tools applied on these traditional materials have improved cataloging efficiency and productivity; they have also enhanced metadata accuracy, consistency, and display, and as a result, facilitated timely and accurate access to valuable library resources for users. The new workflows have been successful, largely due to the support from the department head and staff members who have made valuable suggestions and positive feedback, and also due to the great interest, ability, and persistence of our staff to take on new challenges.

In July 2021, the libraries at the 40 public colleges and universities of the state of Florida, including FIU, will migrate to a new shared Integrated Library System (ILS), Ex Libris' Alma. The new system necessitates new workflows and procedures. So the new challenge for the author is to learn the functions and tools of the new ILS, and develop similar or improved cataloging workflows in the new ILS and continue to adapt as the new system changes.

\section{ACKNOWLEDGEMENTS}

The author would like to express her deepest appreciation to her department head, Rita Cauce. The new workflows would not have been possible without her valuable advice and support. She also provided the backlog information of YBP print approval books in Table 1 and very helpful comments and suggestions for the article.

The author would also like to extend her deepest gratitude to her colleague, Kelly Rowan, who has provided generous help proofreading and editing the paper.

\section{Endnotes}

[1] GenLoad: https://falsc.libguides.com/c.php?g=850314\&p=6454676

[2] WorldCat Updates service:

https://help.oclc.org/Metadata_Services/WorldShare_Collection_Manager/Choose_your_Collecti on_Manager_workflow/WorldCat_updates/About_WorldCat_updates_through_Collection_Man ager/About_WorldCat_updates

[3] OCLC Connexion Client Guides: Batch Processing in the Client: Overview. https://files.mtstatic.com/site_10606/5147/0?Expires=1610991390\&Signature=L4si8hrYiiKEU9 LPD4R4zEroq9a6SbLTsGJqWp8OjqSN6SEXA4lbFaufeHzg2IBJnkq8Eqf9OQfvdbhnNIg6GuK ULDZ7dtrXbi1qxLL6vbepfv87P 4oT2g5LvwyN2faQuqHf00JX RLYYAPhUJ5OmOqTMsAL2v-6KnpRyiH s_\&Key-Pair-Id=APKAJ5Y6AV4GI7A555NA

[4] MarcEdit: https://marcedit.reeset.net/about-marcedit

[5] NOTIS. https://en.wikipedia.org/wiki/NOTIS 
[6] Aleph Integrated Library System. https://exlibrisgroup.com/products/aleph-integratedlibrary-system/

[7] FCLA. https://members.educause.edu/florida-center-for-library-automation

[8] FALSC. https://libraries.flvc.org/

[9] How to Load Records Using the Advanced Generic Vendor Records Loader (file-90).

https://files.mtstatic.com/site_11811/27603/0?Expires=1613765885\&Signature $=r$ rYT404zMSj5o Z1lgXhJN1Ju9wzqo5j3FoI0XkwLFfdn2ln-wTRjKFuIcgVzd9oMcf3XmX0ejRysm3U21K KJnd55NHafUoh6Sfk7e2j6UAUNJ8AZjeK7HUnaETRg ZRrJ5G8LV-uiiRRLKHAdwIgJbmS-6AjPM1TlpYoJqKRrk_\&Key-Pair$\mathrm{Id}=\mathrm{APKAJ} 5 \mathrm{Y} 6 \mathrm{AV} 4 \mathrm{GI} 7 \mathrm{~A} 555 \mathrm{NA}$

[10] OCLC PromptCat Service: https://library.oclc.org/digital/collection/p15003coll74/id/18/

[11] Full-Level Cataloging:

https://www.oclc.org/bibformats/en/onlinecataloging.html\#BCGGBAFC

[12] WorldShare Collection Manager: https://www.oclc.org/en/worldshare-collectionmanager.html

[13] NACO-Name Authority Cooperative Program: https://www.loc.gov/aba/pcc/naco/

\section{References}

Anderson, B. (2015). Updating Alma records with the WorldShare MARC Update Service. Retrieved from https://scholarscompass.vcu.edu/cgi/viewcontent.cgi?article=1035\&context=libraries_pre sent

French, R. B. (2020). Secrets of the save file: Using Connexion and Microsoft Access for efficient batch cataloging projects. Retrieved from https://commons.lib.jmu.edu/cgi/viewcontent.cgi?article=1196\&context=letfspubs

Harden, J. (2017). Batch processes: Using Connexion client, MarcEdit, and Microsoft Access. Retrieved from https://digital.library.unt.edu/ark:/67531/metadc1036580

Lorimer, N. (2012). Unlocking historical audio collections: Collaborative cataloging and batch searching of $78 \mathrm{rpm}$ recordings. Technical Services Quarterly, 29:1, 1-12, DOI: 10.1080/07317131.2011.597682

Riordan, G. \& Baksik, C. M. (2017). OCLC WorldCat Updates (BNS/WMS) implementation. Retrieved from https://wiki.harvard.edu/confluence/pages/viewpage.action?pageId=181077967

Strickler, C. (2017). Testimony: Using MarcEdit and OCLC Connexion to enhance bibliographic records in a batch. Retrieved from https://www.atla.com/blog/testimony-using-marceditand-oclc-connexion-to-enhance-bibliographic-records-in-a-batch/ 


\section{About the author}

Elaine Dong (edong@fiu.edu) is the Database and Metadata Management Librarian at Florida International University Libraries in Miami, Florida. She holds a M.S. in Library and Information Science from McGill University. Her professional interests include eResource management, database maintenance, and data analytics. 